\title{
METODOLOGIAS ATIVAS E QUALIFICAÇÃO DOCENTE: UM ESTUDO DE CASO
}

\author{
Alessandra Cassal dos Santos ${ }^{1}$ \\ Adriana Magedanz ${ }^{2}$
}

Resumo: A educação está em constante metamorfose. E, para auxiliar nessas mudanças, as metodologias ativas buscam facilitar o processo de ensinar. Principalmente no que se referem aos cursos técnicos, há muitos profissionais na função docente, mas sem habilitação pedagógica para tal. $\mathrm{Na}$ contemporaneidade, em função dos avanços percebidos nos diversos setores, o professor deveria ultrapassar o modelo básico e tradicional de ensinar, já que os novos mercados de trabalho estão exigindo, cada vez mais, a formação de um cidadão crítico e capaz de mudar o meio em que está. Neste sentido, o presente artigo tem como objetivo analisar as diferentes percepçóes de um grupo de professores do ensino técnico, na sua grande maioria sem formação didático-pedagógica, enquanto discentes de um curso de pós-graduação lato sensu intitulado Docência na Educação Profissional (DEP). O foco central desta análise está no aspecto relacionado à importância de buscar qualificação docente voltada, especificamente, para o contexto da educação profissional. A realização de um curso de especialização na área de ensino pode fortalecer algumas percepçóes quanto ao universo pedagógico e qualificar práticas de sala de aula, auxiliando docentes e alunos. A pesquisa pode ser definida como um estudo de caso, com caráter descritivo, exploratório e abordagem dos dados de cunho qualitativo. O questionário semiaberto utilizado como ferramenta de coleta dos dados referiu, além de informaçóes gerais sobre os pesquisados, a inserção das metodologias ativas no ensino atual. A investigação também permitiu refletir sobre o quanto o professor precisa sentir-se preparado no quesito ensinar e ainda foi possível constatar a importância das metodologias ativas nesta nova realidade, onde o docente assume o papel de ator coadjuvante frente aos alunos, desencadeando num movimento educacional ativo de ensino.

Palavras-chave: Educação profissional; metodologias ativas; docência; qualificação pedagógica.

1 Bacharel em Enfermagem. Pós-graduada em Saúde da Família. Pós graduanda em Docência na Educação Profissional. Universidade do Vale do Taquari - Univates. Enfermeira.

2 Orientadora. Licenciada em Ciências e Matemática. Especialista em Ensino de Matemática. Mestre em Ensino de Ciências Exatas. Doutoranda em Ensino. Universidade do Vale do Taquari - Univates. Professora. 


\title{
ACTIVE METHODOLOGIES AND TEACHING QUALIFICATION: A CASE STUDY
}

\begin{abstract}
Education is in constant metamorphosis. To assist in these changes, the active methodologies seek to facilitate the process of teaching. Especially as far as technical courses are concerned, there are many professionals teaching but without pedagogical qualification to do so. In contemporary times, due to the advances made in different areas, the teacher should go beyond the basic and traditional way of teaching, since the new labor markets are increasingly demanding the formation of a critical citizen capable of changing the environment where it is. In this sense, the present article aims to analyze the different perceptions of a group of technical education teachers, mostly without didactic and pedagogical training, as students of a post-graduation course latosensu entitled Teaching in Professional Education (DEP). The central focus of this analysis is on the aspect related to the importance of seeking teacher qualification focused specifically on the context of professional education. Doing a specialization course in the area of teaching can strengthen some perceptions regarding the pedagogical universe and qualify classroom practices, assisting teachers and students. The research can be defined as a case study, with descriptive, exploratory character and approach of qualitative data. The semi-open questionnaire used as a data collector tool referred, in addition to general information about the respondents, to the insertion of active methodologies in current teaching. The research also allowed us to reflect on how much the teacher needs to feel prepared to teach and it was still possible to verify the importance of the active methodologies in this new reality, where the teacher assumes the role of supporting actor before the students, triggering an active educational movement of education.
\end{abstract}

Keywords: Professional education; active methodologies; teaching; pedagogical qualification.

\section{CONSIDERAÇÓES INICIAIS}

Metodologias ativas é uma expressão muito corriqueira nos dias de hoje. Ao digitar "metodologias ativas" num portal de buscas na internet, em 0,28 segundos, ele retorna mais de 75.000 resultados. Este resultado permite conjecturar que o tema integra inúmeros estudos e, portanto, suscita curiosidades no que se refere às investigações que a comunidade científica vem desenvolvendo sobre isso, considerando a realidade no mundo contemporâneo.

Um dos desafios dos tempos atuais é formar professores que ultrapassem as barreiras básicas e tradicionais de aprendizado, superando a visão do docente como único protagonista e dono da sabedoria. Nesta nova realidade que aflora, é preciso considerar a formação de um cidadão crítico, reflexivo, engajado nas questões profissionais, humanizado e transformador do meio em que está. Neste sentido, é fundamental o ser humano exercer sua autonomia, com argumentações para mudar a realidade e a sua vida. Para isso, será necessário romper com paradigmas de ensinagem e de aprendizado.

Os professores de ensino profissional, geralmente, são trabalhadores da área e leigos na docência. Possuem vivências consolidadas há anos no mercado de trabalho. Mas, não possuem prática ou qualificação pedagógica, com pouca formação na educação. Paulo Freire (1996) menciona que, para cozinhar, é necessário estar 
familiarizado com a cozinha e seus instrumentos. Da mesma forma, para quem veleja, é necessário ter domínio do barco, velas, vento, etc. Portanto, o professor não necessita estar familiarizado com a educação?

A docência sem o preparo e a habilitação para lecionar, principalmente na educação profissional, é um fato histórico no Brasil (CONTE; PAULA, 2016). Os professores de medicina, por exemplo, geralmente são médicos; os professores de arquitetura são arquitetos. São diferentes profissionais atuando como docentes, mas sem a devida capacitação pedagógica para tal. $\mathrm{O}$ mundo atual necessita de professores que tenham como postura a prática reflexiva e a (auto)crítica. A reflexão traz necessidade em inovar sobre as atuais práticas pedagógicas, buscando o novo. Já a (auto)crítica tem importância, desde o envolvimento dos professores nos debates da sociedade, sobre educação, cultura e outros temas, até o exercício do seu papel neste contexto.

As diversas formas de ensinar deveriam fascinar todo professor. Corroborando Antunes (2007, p.09), "seria tolice pensar que a educação simbolizaria uma ilha pelas ondas fanáticas dessa colossal maré". Há muitos oceanos para serem desbravados dentro do universo pedagógico. Esta realidade, por si só, já tornaria mais agradável e funcional a atuação do professor. No entanto, há muita angústia e insegurança, talvez, em algumas situações, seja até reflexo da preocupação excessiva com o compromisso de lecionar com qualidade e contemplando as necessidades de cada uma das suas turmas.

Para que ocorra esta qualificação nas aulas, é preciso repensar as metodologias de trabalho em sala de aula. É necessário buscar habilidades e competências para estas novas gerações de alunos. O perfil do discente está mudado. A escola também mudou e acaba sobrevivendo, hoje, com expectativas de desempenho muito elevadas em relação aos estudantes. No entanto, ainda existem escolas que seguem o modelo antigo, onde a tarefa dos alunos se restringe a copiar as lições do quadro, conforme orientações do professor. A adesão aos recursos mais modernos de informação e comunicação poderia (e deveria) alterar estas realidades (BARBOSA; MOURA, 2013).

Um possível caminho na busca pela qualificação e inovação do planejamento do ensino está na desacomodação dos envolvidos, sair da zona de conforto pode ser o pontapé inicial desta mudança para, na sequência, assumir uma zona de risco. Aderir à pedagogia crítica, onde o aluno é o protagonista e o professor um mediador, provocador da curiosidade (PRADO et al., 2012).

Conforme Borba e Penteado (2001, p.56):

Alguns professores procuram caminhar numa zona de conforto, onde quase tudo é conhecido, previsível e controlável. [...] Mesmo insatisfeitos, e em geral os professores se sentem assim, eles não se movimentam em direção a um território desconhecido. [...] não conseguem se movimentar para mudar aquilo que não os agrada. Acabam cristalizando sua prática numa zona dessa natureza e nunca buscam caminhos que podem gerar incerteza e imprevisibilidades. Esses professores nunca avançam para o que chamamos de zona de risco $[\ldots]$. 
A educação é, sem dúvida, uma das formas mais eficazes na construção de indivíduos aptos para exercerem as diferentes profissões, bem como no exercício das ações de cidadania. Ela prepara as pessoas para a convivência no mundo, desde o nascimento perpassando toda evolução do raciocínio crítico, sendo esta a diferença que transforma o meio social, o pensar e o interagir com os demais seres humanos.

Diante das considerações apresentadas, o objetivo desta escrita é analisar diferentes percepções em relação à importância de buscar qualificação docente voltada, especificamente, para o contexto da educação profissional. Para tanto, investigou-se um grupo determinado de professores, enquanto discentes de um curso de pós-graduação lato sensu intitulado Docência na Educação Profissional (DEP).

\section{APRENDER... ENSINAR: alguns referenciais teóricos}

De acordo com a Constituição Brasileira (BRASIL, 1988, p. 123), a “[...] educação é um direito de todos, dever do Estado e da família", visando ao desenvolvimento do indivíduo e preparando-o para o exercício da cidadania e qualificação para o trabalho. Falar em educação lembra, na maioria das vezes, a figura do professor. A docência é conhecida como a prática dos processos de ensino e de aprendizagem. O professor é o principal mediador na educação, estimulando, direcionando, redirecionando e promovendo a autonomia do aluno (CONTE; PAULA, 2016).

Das práticas educativas, na organização histórica, emergem as necessidades de diferentes grupos sociais em acessar a educação. A perpetuação de traços coloniais na estrutura social brasileira, na composição dos governos e na administração do público tem fortes raízes rurais e patriarcais (LUCINI; ACILINO, 2007).

A educação popular, na situação do país no início do século, se insere nos movimentos sociais que são tensos. Esta composição busca compreender questões a partir de um quadro político-democrático, onde se manifestam as lutas pela transformação da população a partir do ensino, almejando cidadania e qualidade de vida. O que é possível esperar desta relação de contradições é a transformação, e é o que torna a educação inovadora, apostando que há como transformar também a realidade, a dominação e a ação do dominado (LUCINI; ACILINO, 2007).

Paulo Freire, renomado educador brasileiro, critica a educação como mera transmissão de pensamentos, conforme ele:

Não devemos chamar o povo à escola para receber instrução, postulados, receitas, ameaças, repreensões e punições, mas para participar coletivamente da construção de um saber, que vai além do saber de pura experiência, feito que leve em conta as suas necessidades e o torne instrumento de luta, possibilitando-lhe transformar-se em sujeito de sua própria história (FREIRE, 2001, p. 35). 
E o que emerge desta reflexão inicial? Como a sociedade interpreta as ideias de Freire? E a comunidade escolar? E os professores? São indagações que, certamente, permitiriam outras vertentes intestigativas. Por agora, o que buscamos é averiguar se as metodologias ativas e a qualificação docente podem interferir neste novo modelo de escola, que vem sendo proposto por alguns teóricos.

A vida se tornou complexa mundialmente, há muitos pensando e construindo sua própria história e isso faz com que amplie a demanda na educação. Sendo assim, o professor é o intermediador, e ele pode contribuir para a promoção de autonomia dos alunos ou para a manutenção de comportamentos de controle sobre eles (BERBEL, 2011).

As metodologias ativas entram nesta realidade com a função de despertar a curiosidade, os alunos participam e trazem elementos novos, que até então, talvez, ainda não tivessem sido considerados nas aulas ou na visão do educador. Neste sentido, as contribuições dos estudantes são analisadas e aceitas, valorizando os sentimentos e estimulando as percepções e competências de pertencimento ao estudo, para persistência na educação, e autonomia do educando. O professor atua como facilitador ou orientador, atiçando para que o estudante faça pesquisas, reflita e decida o que empreender para atingir os objetivos estabelecidos (BERBEL, 2011).

Para Marinet et al. (2010), adotar metodologias ativas significa romper com as formas tradicionais de ensino. É a valorização do indivíduo como ser livre, ativo e social, incentivando ainda mais o processo de aquisição do saber, do que o saber propriamente dito. Com relação ao método anterior, centrado no professor, com prática mecanizada, rígida e conteúdo detalhadamente programado, para Morán (2015), foi viável, quando o acesso à informação era difícil, mas hoje, a ciência e as notícias chegam muito rápido. Há inúmeros outros instrumentos facilitadores no processo de ensinar, o que não havia antigamente.

Morán (2015, p.4) afirma que "as metodologias ativas são pontos de partida para avançar para processos mais avançados de reflexão, de integração cognitiva, de generalização, de reelaboração de novas práticas". O mesmo autor sustenta também que o aprendizado se dá a partir de exemplos práticos, situações e problemas que vivenciarão na vida profissional, podendo-se antecipar algumas vivências já durante o curso.

Dentre as principais características dos métodos inovadores de ensino e de aprendizagem é possível apontar o movimento de migração do "ensinar" para o "aprender", no qual o aluno assume a co-responsabilidade pelo seu aprendizado. De forma geral, o foco é do docente para o discente, e este aprendizado pode ocorrer em diversos cenários, combinado ou não com métodos tradicionais, mas vivenciando experiências significativas (SOUZA; IGLESIAS; PAZIN-FILHO, 2014).

A problematização de situações reais confronta o aluno com diversas informações e viabiliza a produção do conhecimento. Emerge, principalmente, com a finalidade de solucionar os problemas verídicos, resultando na promoção do seu próprio aprendizado. Portanto, a problematização e a resolução de problemas 
relacionados a sua área de estudo, é uma das possibilidades na busca pelo envolvimento ativo dos alunos em seu próprio processo de formação (BERBEL, 2011).

O espaço de educar (que pode se dar em qualquer lugar: escola, rua,trabalho, etc) deve dar iniciativa para interação entre os sujeitos, os quais construirão sua própria aprendizagem e seus conhecimentos. Nesta visão, o papel do educador deveria ser apenas o de acompanhar, auxiliando no processo (SAVIANI, 2005).

O educador democrático, não pode negar a capacidade crítica do educando. Aprender criticamente é possível (FREIRE, 1996).

É exatamente neste sentido que ensinar não se esgota no "tratamento" do objeto ou do conteúdo, superficialmente feito, mas se alonga à produção das condições em que aprender criticamente é possível. E essas condições implicam ou exigem a presença de educadores e de educandos criadores, instigadores, inquietos, rigorosamente curiosos, humildes e persistentes (FREIRE, 1996, p.13).

Estamos sempre aprendendo, como nos bem lembra Júnior (2005, p.86):

Quase tudo o que nós vivemos em nossas relações com outras pessoas ou mesmo com o nosso mundo, como no próprio contato direto com a natureza, pode ser, também, um momento de aprendizado. Podemos estar ou não conscientes disto, mas cada troca de palavras, cada troca de gestos, cada reciprocidade de saberes e de serviços com uma outra pessoa, costuma ser também um momento de aprendizagem.

Ou seja, em qualquer local ou situação, com qualquer pessoa, sendo criança ou adulto, é um aprender constante. Para isso, precisamos estar abertos às críticas e também ser críticos, estar com olhar aguçado e inquieto para poder aprender.

\section{TRABALHANDO COM PESQUISA: um pouco da metodologia}

A pesquisa referida neste trabalho pode ser definida como um estudo de caso, por ter diversos aspectos que são peculiares única e exclusivamente desta investigação. Segundo Fonseca (apud GERHARDT; SILVEIRA, 2009, p.39):

[...] pode ser caracterizado como um estudo de uma entidade bem definida [...] Visa conhecer em profundidade o como e o porquê de uma determinada situação que se supõe ser única em muitos aspectos, procurando descobrir o que há nela de mais essencial e característico.

Além disso, tem caráter descritivo exploratório. Leopardi (2002) entende que as pesquisas exploratórias aumentam a experiência de um determinado problema, consistindo também em examinar a primeira aproximação com o tema, criando maior familiaridade com o fato ou fenômeno.

A investigação exploratória é realizada em área na qual há pouco conhecimento acumulado e sistematizado (MORESI, 2003). Silva (2005) acrescenta que pode envolver levantamento bibliográfico, entrevistas com pessoas que tiveram 
experiências práticas com o problema pesquisado e análise de exemplos que estimulem a compreensão.

No que se refere à abordagem dos dados, se considerarmos a objetividade proposta por Gerhardt e Silveira (2009, p.34), aspectos quantitativos presentes em alguns momentos, como ao averiguar o montante alcançado em cada situação investigada e a representatividade do mesmo no contexto a ser analisado, podem auxiliar na formulação de resultados.

Em suma, o contexto exposto inicialmente nos leva para uma pesquisa de cunho qualitativo. Neste sentido, Moreli (2003) vê na pesquisa qualitativa uma relação dinâmica entre o mundo real e o sujeito. Um vínculo indissociável entre o mundo objetivo e a subjetividade do sujeito, que não pode ser traduzido em números. Goldim (2000) infere que a pesquisa qualitativa é essencialmente descritiva e tem como objetivo principal a visão de processos, dando relevante importância ao ambiente e ao papel desempenhado pelo pesquisador. Já Creswel (2007), acredita que a pesquisa qualitativa permite ao pesquisador ter uma visão holística dos fenômenos sociais, pois é realizada no cenário natural dos participantes da pesquisa.

Na parte analítica, Moraes (1999) afirma, na análise textual discursiva, que as categorias são vistas como rubricas ou classes que agrupam determinados elementos reunindo características comuns. No processo de escolha de categorias adotam-se os critérios semântico (temas), sintático (verbos, adjetivos e pronomes), léxico (sentido e significado das palavras - antônimo ou sinônimo) e expressivo (variações na linguagem e na escrita). Este processo permite a junção de um número significativo de informações organizadas em duas etapas: inventário (onde se isolam os elementos comuns) e classificação (onde se divide os elementos e impõem-se organização). A categorização é uma operação de classificação dos elementos de uma mensagem seguindo determinados critérios, ela facilita a análise da informação e é, sem dúvida, uma das etapas mais criativas da análise de conteúdo (MORAES, 1999).

Diante do exposto, definido o método - estudo de caso com caráter exploratório de cunho qualitativo, na sequência, buscar-se-á contextualizar a realidade desta pesquisa que, conforme antes anunciado, envolveu discentes de um curso de pós-graduação lato sensu, que ocorreu numa universidade do Vale do Taquari.

\section{SUJEITOS E PROCESSO: contextualizando a pesquisa}

A realização de um curso de especialização na área de ensino poderia influenciar na performance futura dos envolvidos? Tal indagação reflexiva serviu como ponto de partida para a realização desta pesquisa e, por isso, optou-se em investigar diferentes percepções em relação à importância de buscar qualificação docente voltada, especificamente, para o contexto da educação profissional. Os sujeitos investigados se constituíram num grupo determinado de professores, 
enquanto discentes de um curso de pós-graduação lato sensu intitulado Docência na Educação Profissional (DEP).

Neste sentido, o público alvo da pesquisa desenvolvida foram os pósgraduandos da primeira edição do curso de Especialização lato sensu em Docência na Educação Profissional, realizado numa universidade do Vale do Taquari, no período entre 2016 e 2017. O grupo é constituído por profissionais de diversas áreas, como: jornalismo, enfermagem, nutrição, direito, engenharias, etc. Esta diversidade poderia estimular investigações muito pontuais, mas, no presente trabalho, serviu apenas como mais um elemento característico da pesquisa.

A coleta de dados foi feita através de um questionário estruturado pelo Google Forms, com sete perguntas de respostas obrigatórias, sendo duas objetivas e cinco dissertativas, além de uma questão aberta, para observações livres. O questionário visou a obtenção de diferentes percepções quanto à importância de buscar qualificação docente voltada à educação profissional. O rol de questões foi enviado no mês de janeiro de 2018, tendo retorno de 34 respondentes de um total de 70 enviados. A Figura 1 ilustra o modelo de questionário utilizado na pesquisa. Após, na análise da pesquisa, os alunos serão identificados por ordem numérica.

Figura 1: Modelo do questionário utilizado na pesquisa

Questionário para pesquisa - Pós-Graduação Lato Sensu

Docência na Educação Profissional (DEP) - Percepções dos discentes da turma 1

1. Sexo

( ) Masculino

( ) Feminino

2. Qual sua formação? (Citar graduação $e$, se tiver, cursos de especialização exceto DEP.)

3. Dentre as opções abaixo, qual o seu periodo de experiência docente?

( ) Zero - Não tenho experiência nenhuma na atuação como professor(a).

( ) Tenho alguma experiência, no limite umano.

( ) Mais de um ano, no limite dois anos.

( ) Mais de dois anos, no limite cinco anos.

( ) Mais que cinco anos, no limite dez anos

( ) Mais que dez anos atuando como professor(a).

4. Por que a procura pela especialização em Docência na Educação Profissional (DEP)?

5. A atuação na docência, especialmente no que tange ao uso de metodologias diferenciadas em sala de aula, foi influenciada pela especialização DEP? Justifique. (Caso não atue como professor (a), assinale apenas um " $\mathrm{X}$ " no espaço abaixo.)

6. Em caso de resposta positiva na questão anterior (número 5), ou seja, se houve mudança na sua metodologia de trabalho em sala de aula, foi possivel perceber também alterações comportamentais dos alunos neste periodo? Justifique, descrevendo alguma(s). (Caso não atue como professor (a) ou a resposta anterior foi negativa, assinale apenas um " $X$ " no espaço abaixo.)

7. Como são as suas aulas? Faça uma breve descrição. (IMPORTANTE! Se possivel, caracterize-as antes e depois de cursar a especialização DEP.)

8. Observações livres.

Fonte: Das autoras, 2018. 
Concluída a coleta de dados, a etapa seguinte consistiu na análise do conteúdo das respostas dos questionários, buscando compreender e complementar a amplitude da temática escolhida: educação profissional.

\section{DISCUSSÃO E ANÁLISE DOS DADOS}

Uma vez definido o contexto da pesquisa e realizada a coleta de dados, iniciou-se a parte referente a análise do conteúdo das respostas expressas no questionário, Nesta etapa inicial, foram verificadas possibilidades de análise e, para isso, alguns aspectos retratados numericamente contribuíram na caracterização dos sujeitos investigados. Por exemplo, do total de participantes respondentes da pesquisa, 47,1\% eram do sexo feminino, enquanto que o restante eram homens, ou seja, a diferença percentual mínima não fomenta nenhum tipo de investigação no quesito gênero.

Outro questionamento levantado no estudo se referiu à formação profissional dos respondentes. Neste sentido, para facilitar a interpretação dos dados, utilizouse a mesma divisão adotada pela instituição de ensino alvo da pesquisa ${ }^{3}$. Portanto, a distribuição das respostas referentes a cada curso de graduação citado ficou assim categorizada: Centro de Ciências Humanas e Sociais (CCHS), Centro de Gestão Organizacional (CGO), Centro de Ciências Exatas e Tecnológicas (CETEC) e Centro de Ciências Biológicas e da Saúde (CCBS). O Gráfico 1 ilustra esta categorização.

Gráfico 1: Categorização dos cursos citados na formação profissional

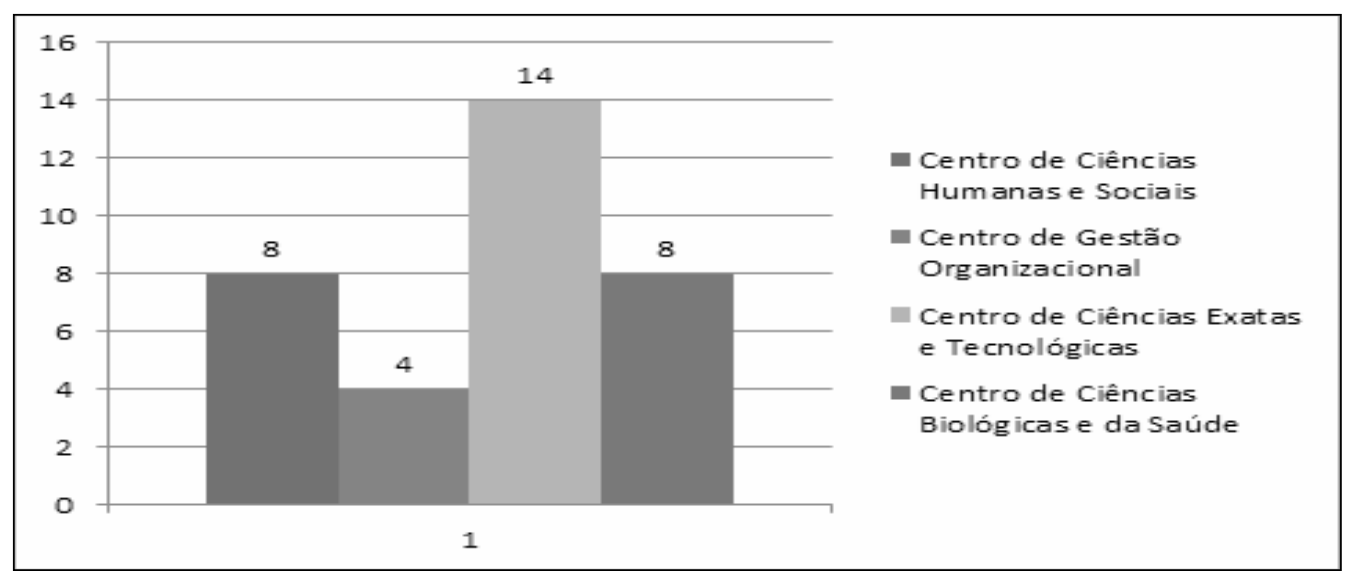

Fonte: Das autoras, 2018.

Com relação ao Gráfico 1, a opção CETEC aparece em destaque, com 14 representantes, mesmo este não sendo o objetivo da pesquisa, seria possível fazer

3 Para melhor compreender a divisão proposta, a informação está disponível no site: $<$ www.univates.br/institucional/centros $>$. 
suposições acerca desta realidade. Por exemplo: são inúmeros os cursos técnicos na área de Ciências Exatas, como Eletroeletrônica, Mecânica, Informática, etc. Neste caso, a exigência é de docentes profissionais formados em cursos superiores na área das engenharias.

Outra constatação possibilitada pela coleta de dados, e que também vem ao encontro da formação universitária, está na relação da área de graduação cursada e o ensino. Somente $11,8 \%$, ou seja, quatro do total de respondentes são formados em cursos vinculados à licenciatura.

E, mesmo com a grande maioria dos respondentes sendo oriundo de curso superior não relacionado à licenciatura, $85 \%$ do grupo respondente está há mais de dois anos atuando como professor(a). Neste caso, até podem ser considerados com experiência, mas não tem formação na área do ensino. Como comprovada nas discussões anteriores os quais não tem formação na área de docência. O Gráfico 2 especifica esta situação.

Gráfico 2: Tempo de atuação na docência

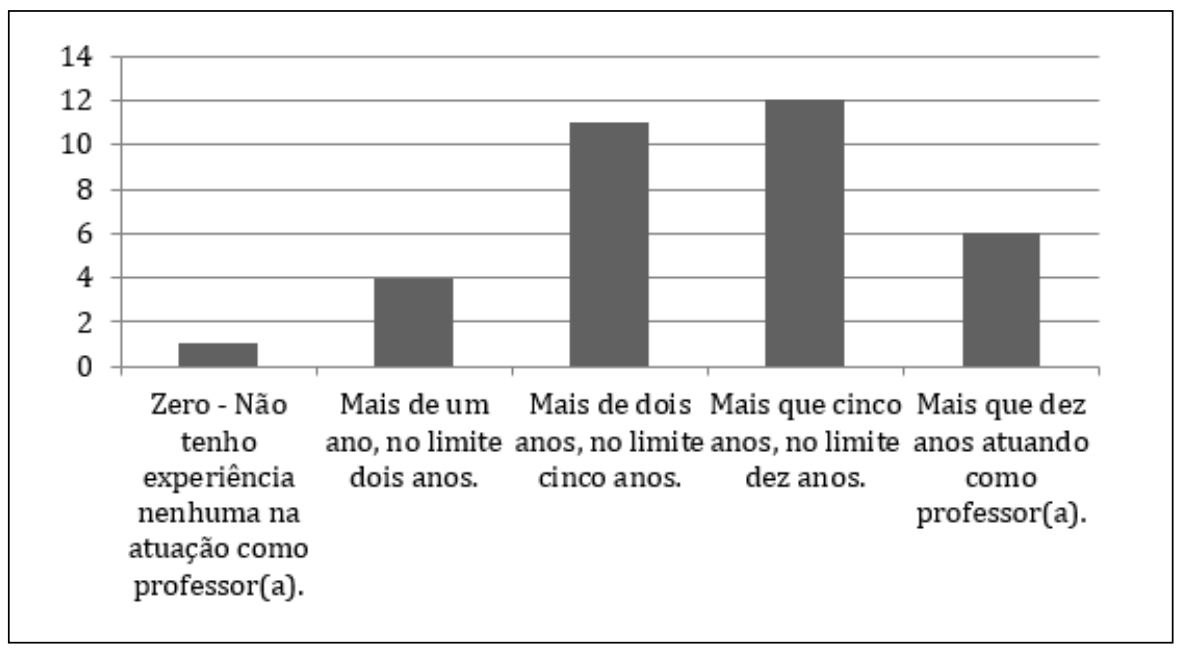

Fonte: Das autoras, 2018.

Além das questões objetivas, cujos resultados estão relacionados com os gráficos já apresentados, o questionário, da mesma forma, envolveu algumas perguntas dissertativas, que objetivaram identificar os motivos pelos quais estes profissionais de diferentes áreas, que também atuam como professores em cursos técnicos buscaram a qualificação através de um curso de especialização na área da docência profissional. $\mathrm{Na}$ análise destas respostas, foi possível agrupar alguns resultados, trabalhando com a ideia de categorização ou unitarização.

Assim, na indagação que traz o contexto justificativo, ou o porquê de realizar uma pós-graduação vinculada ao ensino, as respostas, na grande maioria, remetem a ideia de qualificação profissional, formação pessoal, qualidade das aulas e oportunidade de experiência. Neste sentido, foi estruturado um quadro que, 
na visão adotada por esta pesquisa e de forma resumida, aborda o contexto das diferentes respostas (QUADRO 1).

Quadro 1: Motivos pela busca do curso de especialização em DEP

\begin{tabular}{|c|c|c|}
\hline $\begin{array}{c}\text { Categoria ou unidade } \\
\text { de análise }\end{array}$ & Justificativa & $\begin{array}{c}\text { Exemplos de abordagem no } \\
\text { questionário }\end{array}$ \\
\hline $\begin{array}{l}\text { QUALIFICAÇÃO } \\
\text { PROFISSIONAL }\end{array}$ & $\begin{array}{c}\text { Dentre as palavras mais citadas } \\
\text { podemos destacar:aperfeiçoamento, } \\
\text { aperfeiçoar, aprimorar e } \\
\text { especialização. Este grupo, junto, } \\
\text { totalizou } 18 \text { citações, remetendo } \\
\text { a ideia de busca pela qualificação } \\
\text { profissional. }\end{array}$ & $\begin{array}{l}\text { "[...] aperfeiçoamento profissional" } \\
\text { (ALUNO 12, grifo nosso). } \\
\text { "[...] qualificaşão dos métodos } \\
\text { de ensino" (ALUNO 13, grifo } \\
\text { nosso). }\end{array}$ \\
\hline $\begin{array}{l}\text { FORMAÇÃO } \\
\text { PESSOAL }\end{array}$ & $\begin{array}{l}\text { Conhecimentos, aperfeiçoamentos } \\
\text { e atualização foram outros motivos } \\
\text { presentes nas respostas. Estas } \\
\text { palavras foram citadas } 12 \text { vezes. }\end{array}$ & $\begin{array}{l}\text { "Em primeiro lugar pelo } \\
\text { desejo de exercer a profissão } \\
\text { de professora. Assim, precisava } \\
\text { me preparar para isso, com } \\
\text { conhecimentos sobre: gestão, } \\
\text { didática, planejamento, etc" } \\
\text { (ALUNO 16, grifo nosso). }\end{array}$ \\
\hline $\begin{array}{l}\text { QUALIDADE DAS } \\
\text { AULAS }\end{array}$ & $\begin{array}{l}\text { Associada a outras palavras, como } \\
\text { qualificação, melhorar e somar, } \\
\text { a palavra qualidade foi citada } 10 \\
\text { vezes. Voltada para o aspecto } \\
\text { pedagógico, remete a ideia de } \\
\text { qualificação das aulas. }\end{array}$ & $\begin{array}{l}\text { "Para melhorar a qualidade das } \\
\text { minhas aulas" (ALUNO 01, } \\
\text { grifo nosso). }\end{array}$ \\
\hline $\begin{array}{l}\text { OPORTUNIDADE E } \\
\text { EXPERIÊNCIA }\end{array}$ & $\begin{array}{l}\text { As duas palavras, oportunidade e } \\
\text { experiência, foram citadas } 7 \text { vezes, o } \\
\text { que permite verificar outro aspecto } \\
\text { considerado pelos respondentes. }\end{array}$ & $\begin{array}{l}\text { "Fiz para abrir novas portas } \\
\text { e oportunidades de trabalho" } \\
\text { (ALUNO 04, grifo nosso). }\end{array}$ \\
\hline
\end{tabular}

Fonte: Das autoras, 2018.

Ao efetuar a análise, especificamente desta questão, que enfoca o motivo de cursar a pós em DEP, outro ponto foi constatado e merece ser apontado. Alguns dos profissionais discentes da turma buscaram a qualificação apenas pelo fato da instituição a qual pertencerem exigir tal formação para que permaneçam na docência. Ilustrando esta realidade, seguem algumas citações ipsis litteris dos respondentes: "Obrigatório e pq não tinha formação pedagógica" (ALUNO 02); "Por exigência da coordenação do curso" (ALUNO 22);“"Orientação da coordenação” (ALUNO 24); "Aprimoramento da docência e coordenação de curso" (ALUNO 33).

Quanto a atuação na docência, especialmente no que tange ao uso de metodologias diferenciadas em sala de aula, a pesquisa identificou influências advindas do curso de especialização em DEP. Do total de respondentes, 59\% notaram diferença em suas aulas antes, durante e após a realização deste pós. Outros 
26,5\%, não notaram diferença em suas aulas, mas alegaram que já trabalhavam com metodologias diversificadas, antes da realização do curso. Por fim, vale deixar registrado que $14,7 \%$ não atuam ou atuavam como professores e, por isso, não responderam a este questionamento.

Dos respondentes que notaram muitas diferenças em suas aulas com a realização do curso de especialização em DEP, a grande maioria alega que, antes, as aulas eram mais expositivas e de forma convencional. Hoje, utilizam outros recursos, na maioria vinculada as metodologias ativas. O Quadro 2, resumidamente, expõe um paralelo comparativo.

Quadro 2: Influências nas aulas com a realização do curso de especialização em DEP

\begin{tabular}{|c|c|}
\hline Antes do curso de especialização em DEP & $\begin{array}{c}\text { Depois do curso de especialização em } \\
\text { DEP }\end{array}$ \\
\hline $\begin{array}{l}\text { - Aulas expositivas e dialogadas; } \\
\text { - Slides- conceitos; } \\
\text { - Aulas tradicionais: apresentação oral, pro- } \\
\text { vas; } \\
\text { - Enfase na teoria e pouca prática; } \\
\text { - Pouca participação do aluno em sala de aula; } \\
\text { - Pouco interesse na vida pessoal do aluno - } \\
\text { - tratamento igual para todos; } \\
\text { - Tema de casa. }\end{array}$ & $\begin{array}{l}\text { - Interação e participação dos alunos; } \\
\text { - Sala de aula invertida; } \\
\text { - Interações com outros professores; } \\
\text { - Trabalhos práticos; } \\
\text { - Técnicas como world café; } \\
\text { - Mapa conceitual; } \\
\text { - PeerInstructions; } \\
\text { - Problematização; } \\
\text { - Filmes e vídeos em sala de aula; } \\
\text { - Jogos; } \\
\text { - Teatros; } \\
\text { - Fóruns de discussões; } \\
\text { - Brainstorming. }\end{array}$ \\
\hline
\end{tabular}

Fonte: Das autoras, 2018.

Ao analisar o Quadro 2, dentre as diferentes percepções, vale ressaltar que os apontamentos referentes as mudanças constatadas pelos professores discentes do curso ficam evidenciadas. No olhar proporcionado pela análise destes resultados, a metodologia para ensinar e aprender dentro da sala de aula sofreu influências e, quiçá, qualificou a atuação docente. Antes, formas tradicionais de ensino serviam como modelo. Agora, depois de concluir o curso de especialização em DEP, algumas metodologias são inseridas no cotidiano pedagógico, revolucionando a sala de aula, tornando o momento de aprendizagem mais dinâmico, interativo e exclusivo, pois cada aula é única.

A parte final do questionário permitiu aos respondentes contribuírem com observações livres. As respostas coletadas neste item apontam para a importância da realização do curso. Diante da variedade do material empírico presente nas escritas, optou-se em apresentar esta nova realidade também em forma de um quadro resumo, cuja organização seguiu um novo critério de categorização (QUADRO 3). 
Quadro 3: Conteúdo das observações livres presentes nos questionários

\begin{tabular}{|c|c|c|}
\hline $\begin{array}{l}\text { Categoria ou } \\
\text { unidade de análise }\end{array}$ & Justificativa & $\begin{array}{c}\text { Exemplos de abordagem no } \\
\text { questionário }\end{array}$ \\
\hline AULAS & $\begin{array}{c}\text { Percebeu-se observações } \\
\text { pertinentes e que evidenciam que } \\
\text { a preparação para lecionar é de } \\
\text { suma importância. As palavras } \\
\text { mais citadas foram relacionadas à } \\
\text { turma, professor, aula, docência, } \\
\text { educação. Num total de } 17 \\
\text { citações. }\end{array}$ & $\begin{array}{l}\text { "Por todo o conteúdo desenvolvido } \\
\text { ao longo da Pós DEP percebe-se } \\
\text { a importância para a formação } \\
\text { do professor. Com destaque para } \\
\text { as metodologias trabalhadas que, } \\
\text { com certeza, enriquecem as aulas e } \\
\text { trocas de conhecimento" (ALUNO } \\
\text { 16). }\end{array}$ \\
\hline METODOLOGIAS & $\begin{array}{l}\text { Extraíram-se relatos que apontam } \\
\text { as metodologias como auxílio } \\
\text { nas aulas e como ferramentas } \\
\text { eficientes na busca pelo } \\
\text { conhecimento. Metodologias, } \\
\text { ferramentas, diferentes e } \\
\text { criatividade, foram também as } \\
\text { mais citadas da questão. Num total } \\
\text { de } 14 \text { citações. }\end{array}$ & $\begin{array}{l}\text { “Esta pós em docência foi } \\
\text { extremamente positiva no âmbito } \\
\text { de sala de aula, porque através } \\
\text { dela foi possível refletir sobre } \\
\text { várias áreas das quais não tinha } \\
\text { um completo conhecimento } \\
\text { anterior (até porque na graduação } \\
\text { não foi passado), especialmente } \\
\text { ferramentas pedagógicas e novas } \\
\text { metodologias” (ALUNO 3). }\end{array}$ \\
\hline ATUALIZAÇÃO & $\begin{array}{c}\text { Entende-se que a atualização } \\
\text { profissional é necessária para o } \\
\text { ensino. As palavras relacionadas } \\
\text { a conhecimento, aprendizagem, } \\
\text { atualização, novidades e } \\
\text { aperfeiçoamento foram citadas } 8 \\
\text { vezes. }\end{array}$ & $\begin{array}{c}\text { “A Pós DEP foi muito boa } \\
\text { para atualização profissional e } \\
\text { pessoal além das novidades em } \\
\text { metodologias ativas" (ALUNO 11). }\end{array}$ \\
\hline DESAFIOS & $\begin{array}{c}\text { Evidenciou-se os desafios de } \\
\text { lecionar. As palavras relacionadas } \\
\text { a desafio, adequações, problemas, } \\
\text { adaptações e necessidade foram } \\
\text { citadas } 7 \text { vezes. }\end{array}$ & $\begin{array}{l}\text { "A busca de melhorar como } \\
\text { docente é contínua até porque } \\
\text { cada semestre, cada turma, cada } \\
\text { aluno terão diferentes necessidades, } \\
\text { diferentes desempenhos, } \\
\text { diversidade cultural, portanto um } \\
\text { novo desafio que se tem a cada } \\
\text { período" (ALUNO 20). }\end{array}$ \\
\hline
\end{tabular}

Fonte: Das autoras, 2018.

Tendo em vista que esta não era uma pergunta obrigatória, apenas observações livres, não houve participação de todos os pesquisados. Vale ressaltar que,dos que responderam,muitos deixaram observações interessantes e, por isso, socializamos alguns excertos.

Todos os professores deveriam ter a oportunidade de fazer este aperfeiçoamento. Vale muito a pena. Me senti muito mais segura na tarefa/ no desafio de ser professora. Tenho convicção de que graças ao curso sou 
uma professora melhor do que teria sido e estarei sempre buscando inovar (ALUNA 04).

A pós abriu um leque de conhecimento e vantagens para amar cada vez mais o que faço. (ALUNO 01).

Adorei o POSDEP. Além de me reintegrar na Educação, deu-se ferramentas para atuar num nível mais alto do Magistério (ALUNO 09).

Diante do exposto, na realidade apresentada, foi possível averiguar que é de grande valia a realização de um curso de especialização na área do ensino, neste caso, em especial, o pós-graduação lato sensu intitulado Docência na Educação Profissional (DEP). As contribuições do mesmo em sala de aula, como o incremento das metodologias ativas no ensino, tornam o aprendizado mais cativante e menos artificial, fazendo do aluno um agente ativo do seu próprio conhecimento.

\section{CONSIDERAÇÓES FINAIS}

A educação não é um tema simples de ser estudado. É muito complexo. Como mencionado no início desta escrita, há muitos falando sobre metodologias ativas, por exemplo, então é preciso estudar para compreender.

Por outro lado, apenas a inserção de novas metodologias em sala de aula não transforma o mundo da educação. Promover a motivação em alunos e professores é uma tarefa árdua e requer olhares fieis para alcançar a tão almejada transformação.

O professor precisa sentir-se preparado no quesito ensinar (assim como o marinheiro na questão navegar, que necessita conhecer mares e ventos). São pequenos detalhes que podem contribuir na obtenção máxima de benefícios intermediados pelas metodologias na formação profissional dos alunos. Assim, é imprescindível haver engajamento, motivação e muita responsabilidade para atuar neste universo repleto de possibilidades, como é o ensino.

$\mathrm{Na}$ investigação científica aqui apresentada, foi possível constatar a importância do aperfeiçoamento profissional, que diversifica estratégias de ensino, como as metodologias ativas, impulsionando a qualidade da educação atual. Deste modo, o professor necessita assumir também um posicionamento de formador humanista com o educando e compreender-se como um dos agentes da mudança no processo educacional.

Por fim, os resultados expressos neste trabalho levam a crer que a forma de ensinar evoca mudanças e a busca pela qualificação docente é um aspecto pertinente a este contexto. Cabe ao professor acreditar em novas possibilidades e aderir (ou não) as oportunidades de ser um interlocutor de possíveis metamorfoses educacionais. 


\section{REFERÊNCIAS}

BARBOSA, Eduardo Fernandes; MOURA, Dácio Guimarães de. Metodologias ativas de aprendizagem na educação profissional e tecnológica. B. Tec. Senac, Rio de Janeiro, v. 39, n.2, p.48-67, maio/ago. 2013.

BERBEL, Neusi Aparecida Navas. As metodologias ativas e a promoção da autonomia de estudantes. Semina: Ciências Sociais e Humanas, Londrina, v. 32, n. 1, p. 25-40, jan./ jun. 2011.

BRASIL. [Constituição (1988)] Constituição da República Federativa do Brasil: texto constitucional promulgado em 5 de outubro de 1988, com as alterações determinadas pelas emendas constitucionais de revisão nos 1 a 6/94, pelas emendas constitucionais nos 1/92 a 91/2016 e pelo decreto legislativo no 186/2008. Brasília: Senado Federal, Coordenação de Edições Técnicas, 2016.

BORBA, Marcelo de Carvalho; PENTEADO, Miriam Godoy. Informática e Educação Matemática. Belo Horizonte: Autêntica Editora, 2001.

CONTE, Maria Beatriz Franze, PAULA, Maria AngelaBoccara de. A docência e o ensino técnico. Educação em Debate, Fortaleza, ano 38, no 72 - jul./dez. 2016.

CRESWEL, John W. Projeto de pesquisa: métodos qualitativo, quantitativo e misto. Porto Alegre: Artmed, 2007.

FREIRE, Paulo. Pedagogia da autonomia: saberes necessários à prática educativa. São Paulo: Paz e Terra, 1996. Coleção Leitura.

. Política e educação. 5. ed. São Paulo: Cortez, 2001.

GERHARDT, Tatiana Engel; SILVEIRA, Denise Tolfo (Orgs.). Métodos de pesquisa. Universidade Aberta do Brasil - UAB/UFRGS. Curso de Graduação Tecnológica Planejamento e Gestão para o Desenvolvimento Rural da SEAD/UFRGS. Porto Alegre: Editora da UFRGS, 2009.

GOLDIM, José Roberto. Manual de iniciação à pesquisa em saúde. Porto Alegre: Da Casa, 2000.

JÚNIOR, Luiz Antônio Ferraro (Org.). Encontros e Caminhos: formação de educadora(res) ambientais e coletivos educadores. Brasilia MMA. Diretoria de Educação Ambiental, 2005. Disponível em: <www.mma.gov.br/estruturas/educamb/_arquivos/ encontros.pdf $>$. Acesso em: $21 / \mathrm{março} / 2018$.

LEOPARDI, Maria Tereza. Metodologia da pesquisa em saúde. 2. ed. Florianópolis: UFSC, 2002.

LUCINI, Marizete; ACILINO, Antônio Clésio. Ensinar e aprender na educação do campo: processos históricos e pedagógicos em relação. Cad. Cedes, Campinas, vol. 27, 
n. 72, p. 177-195, maio/ago. 2007 177. Disponível em: <www.scielo.br/pdf/ccedes/ v27n72/a05v2772>. Acesso em: 19/janeiro/2018.

MARIN, Maria José Sanches; LIMA, Edna Flor Guimarães; PAVIOTTI, Ana Beatriz;MATSUYAMA, Daniel Tsuji; SILVA, Larissa Karoline Dias da; GONZALEZ, Carina; DRUZIAN, Suelaine; ILIAS, Mércia. Aspectos das fortalezas e fragilidades no uso das metodologias ativas de aprendizagem.Revista Brasileira de Educação Médica. 34 (1) : $13-20 ; 2010$.

MORAES, Roque. Análise de conteúdo.Revista Educação. Porto Alegre, v. 22, n. 37, p. 7-32, 1999.

MORÁN, José. Mudando a educação com metodologias ativas. Coleção mídias contemporâneas. Convergências midiáticas, educação e cidadania: aproximações jovens. Vol. II. Carlos Alberto de Souza e Ofelia Elisa Torres Morales (orgs.). PG: Foca FotoPROEX/UEPG, 2015.

MORESI, Eduardo (Org.) Metodologia da pesquisa. Universidade Católica de Brasília - UCB. Pró-Reitoriade Pós-Graduação - PRPG. Programa de Pós-Graduação Stricto Sensuem Gestão do Conhecimento e Tecnologia da Informação. Brasília, 2003.

PRADO, Marta Lenise; VELHO, Manuela Beatriz; ESPÍNDOLA, Daniela Simon; SOBRINHO, Sandra Hilda; BACKES, Vânia Marli Schubert. Arco de Charles

Maguerez: refletindo estratégias de metodologia ativa na formação de profissionais de saúde. Escola Anna Nery, v. 16, n. 1, p. 172-177, 2012.

SAVIANI, Dermeval. As concepções pedagógicas na história da educação brasileira. Texto elaborado no âmbito do projeto de pesquisa "O espaço acadêmico da pedagogia no Brasil", financiado pelo CNPq, para o "projeto 20 anos do Histedbr". Campinas, 25 de agosto de 2005.

SILVA, Edna Lúcia da; MENEZES, EsteraMuszkat. Metodologia da pesquisa e elaboração de dissertação. 4. ed. rev. atual. Florianópolis: UFSC, 2005.

SOUZA, Cacilda da Silva; IGLESIAS, Alessandro Giraldes; PAZIN-FILHO, Antônio. Estratégias inovadoras para métodos de ensino tradicionais aspectos gerais. Medicina. Ribeirão Preto; 2014. 